\title{
Frequency of intestinal parasites among food-handlers in Khartoum, Sudan
}

\author{
M.A. Babiker, ${ }^{1}$ M.S.M. Ali ${ }^{2}$ and E.S. Ahmed ${ }^{1}$
}

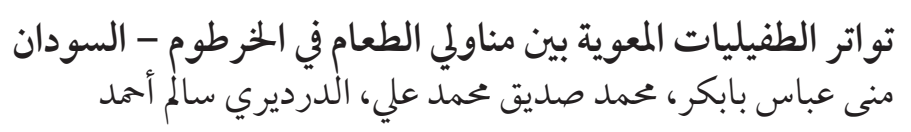

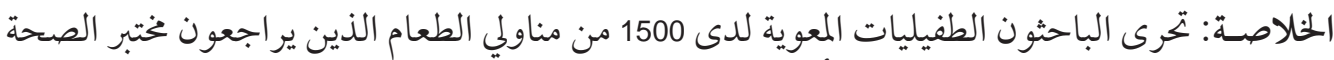

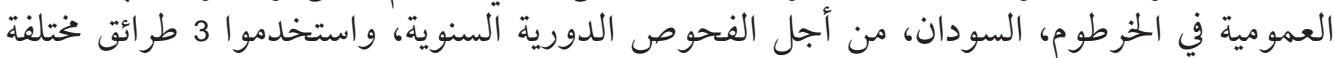

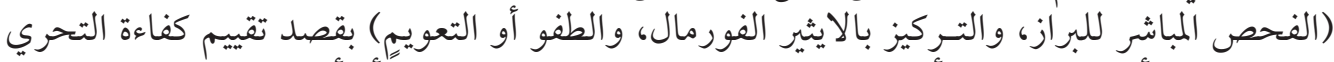

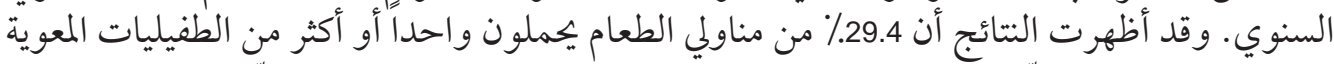

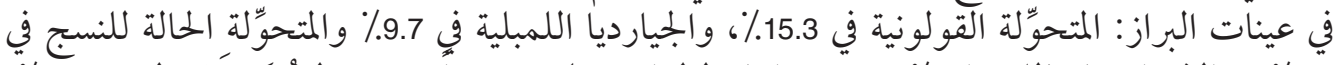

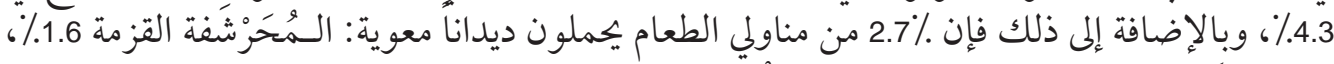

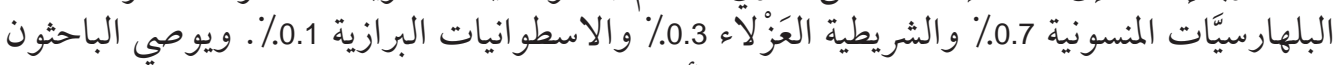

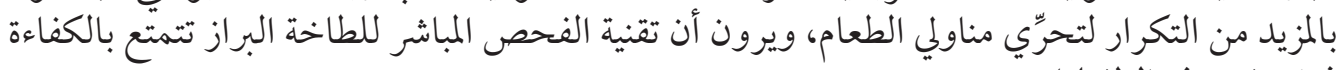
في كشف هذه الطفيليات.

ABSTRACT Food-handlers $(n=1500)$ attending the public health laboratory in Khartoum, Sudan, for annual check-ups were screened for intestinal parasites by 3 different techniques (direct faecal examination, formol-ether concentration and floatation) to evaluate the adequacy of annual screening. Results showed that $29.4 \%$ of food-handlers were harbouring intestinal protozoa in stool samples: Entamoeba coli in $15.3 \%$, Giardia lamblia in $9.7 \%$, and Enta. histolytica in $4.3 \%$. Moreover, $2.7 \%$ of food-handlers harboured intestinal helminths: Hymenolepis nana (1.6\%), Schistosoma mansoni $(0.7 \%)$, Taenia saginata $(0.3 \%)$ and Strongyloides stercoralis $(0.1 \%)$. We recommend more frequent screening of foodhandlers and that the direct faecal smear technique is efficient for the detection of such parasites.

\section{Fréquence des parasites intestinaux chez les personnes manipulant des aliments à Khartoum (Soudan)}

RÉSUMÉ Des personnes appelées à manipuler des aliments $(n=1500)$, qui s'étaient rendues au laboratoire de santé publique de Khartoum (Soudan) pour un bilan de santé annuel ont fait l'objet d'un dépistage des parasites intestinaux par trois techniques différentes (examen direct des selles, concentration par un mélange éther-formol et flottation), dans le but d'évaluer la pertinence d'un dépistage annuel. Les résultats ont montré que les échantillons de selles de $29,4 \%$ des sujets contenaient des protozoaires intestinaux : Entamoeba coli dans 15,3\% des cas, Giardia lamblia dans 9,7\% et Enta. histolytica dans 4,3\%. En outre, 2,7\% des sujets avaient des helminthes intestinaux: Hymenolepis nana $(1,6 \%)$, Schistosoma mansoni $(0,7 \%)$, Taenia saginata $(0,3 \%)$ et Strongyloides stercoralis $(0,1 \%)$. Nous recommandons un dépistage plus fréquent des personnes manipulant des aliments et l'examen direct du frottis fécal comme méthode efficace de détection de ces types de parasites.

\footnotetext{
${ }^{1}$ Department of Microbiology and Parasitology, College of Medicine, University of Juba, Sudan (Correspondence to M.A. Babiker:muna_abbas@yahoo.com).

${ }^{2}$ Department of Haematology, Faculty of Medical Laboratory Sciences, Al-Neelain University, Khartoum, Sudan. Received: 11/03/07; accepted: 10/05/07
} 


\section{Introduction}

Parasitic intestinal infections continue to be an important cause of morbidity and mortality in the developing world [1-5]. The most common intestinal helminths leading to digestive disorders include Taenia saginata, Hymenolepis nana, Ascaris lumbricoides, Strongyloides stercoralis, Trichuris trichiura, Enterobius vermicularis and hookworms [1], and are usually transmitted from contaminated food or water or from the environment. The most common protozoans reported to lead to digestive disorders include Giardia lamblia and Entamoeba histolytica [1]. Outbreaks of protozoan infections in humans have been linked to contaminated food from improper environmental sanitation and to inadequate personal hygiene by food-handlers [6]. In countries where the infection is widespread, most cases infected with $G$. lamblia were found to be asymptomatic $[7,8]$. Enta. histolytica is associated with poor socioeconomic conditions and unhygienic habits, as well as malnutrition in developing countries. According to the World Health Organization (WHO), approximately 500 million people worldwide suffer from amoebiasis, with an annual mortality between 40000 and 110000 [9]. Man is undoubtedly the most important reservoir of Enta. histolytica, passing virulent cysts that are transmitted chiefly by ingestion of contaminated food or water or through direct contact [1].

Most of the pathogenic organisms known to cause diarrhoea are transmitted by the faeco-oral route [10]. The WHO scientific group on the changing pattern of food hygiene problems, which met in Geneva in 1978, highlighted that many of the risks connected with microbial or parasitic contamination had diminished because of the concerted efforts of food hygiene services and producers [11]. Nonetheless, parasitic infections in food-handlers, which are often asymptomatic, may pose a real threat to those who are more susceptible to infection.

In Sudan, food-handlers are screened annually for parasitic infections. The aim of this study was to determine the infection rate among Sudanese food-handlers in order to evaluate the efficiency of the methods and duration of annual screening (12 months) performed by the health authority.

\section{Methods}

This study took place in the Ministry of Health public health laboratory in Khartoum, Sudan, during the period November 2003 to October 2005.

\section{Sample}

A total of 1500 food-handlers who attended for annual check-ups during the study period were selected by systematic sampling by taking the first 20 individuals attending for the check-up daily. The sample size was calculated using Epi-Info, version 6, based on a population size in Khartoum state of 5206000 , expected frequency of $32.3 \%$ (derived from an earlier study) and worst accepted rate of $35 \%$ as: $N=(22 \times$ $p \times Q) / 0.052$; where $p=$ prevalence rate of intestinal parasites, $N=$ sample size and $Q$ $=1-p$.

Informed consent was obtained from each individual, and the ethical clearance committee at College of Medicine, University of Juba, approved the study. Selected individuals provided personal and occupational data and a stool sample which was collected into a labelled container.

\section{Laboratory methods}

Three different methods were used for examination of stool samples: direct faecal ex- 
amination, the formol-ether concentration technique and the floatation technique.

Direct microscopic examination of the sample was carried out in a systematic manner using a $4 \times$ objective lens to select the area to be screened, followed by a $10 \times$ objective lens to locate any parasitic objects. Suspicious objects were identified under a $40 \times$ objective lens. Then 2 drops of Lugol solution were added to facilitate identification of undifferentiated protozoan cysts and specimens were re-examined 5 minutes later [1].

The formol-ether concentration technique was performed by adding $1 \mathrm{~g}$ of faeces to $5 \mathrm{~mL}$ of formalin $(10 \%)$, which was emulsified and strained, and the filtrate centrifuged for $2 \mathrm{~min}$ at $3000 \mathrm{rpm}$. Then 1 $\mathrm{mL}$ of sedimented faeces and $9 \mathrm{~mL}$ of $10 \%$ formalin solution were added to $3 \mathrm{~mL}$ of ethyl acetate and centrifuged further for 2 min at $2000 \mathrm{rpm}$. The upper 3 layers were decanted by inverting the tube and the last drop was allowed to fall back into the tube. Next, the filtrate was allowed to sediment by gravity for $15 \mathrm{~min}$, prepared, examined and identified as in the direct smear technique [1].

The floatation technique was performed by adding $1 \mathrm{~g}$ of faeces to $3.5 \mathrm{~mL}$ of zinc sulfate solution, which was emulsified and the resulting suspension was strained. Then a clean cover glass was placed on top of the tube and the suspension was left undisturbed for $30 \mathrm{~min}$ to give time for cysts and eggs to float. The cover glass was then pulled upwards carefully from the tube and placed face downwards on the slide. Thereafter, the sample was prepared, examined and identified as in the direct smear technique [1].

\section{Analysis}

The data were analysed using SPSS, version 10. Descriptive statistics were used to sum- marize the data. For comparison of proportions, the chi-squared test was used.

\section{Results}

The total number of screened food-handlers included in the study was 1500; the majority were males $(92.9 \%)$. The age distribution of the screened individuals showed $6.9 \%$ were aged $<21$ years, $42.0 \%$ were $21-30$ years, $35.5 \%$ were $31-40$ years, $11.6 \%$ were $41-50$ years and $4.0 \%$ were $\geq 51$ years old. The majority were residents of Khartoum (56.4\%), 39.3\% were from Bahri and $4.3 \%$ from Omdurman. Regarding their occupation, $44.3 \%$ worked in groceries, $25.2 \%$ in cafeterias and restaurants, $9.3 \%$ were bakers, $7.5 \%$ were labourers at food preparation factories (e.g. cakes, sweets and drinks factories), 5.7\% were butchers, $4.5 \%$ were vegetable- and fruit-sellers, $2.1 \%$ were milk- and poultry-sellers and $1.4 \%$ worked in hotels. The majority of the sample had work experience $\leq 5$ years $(74.5 \%), 16.6 \%$ had experience between 6 and 10 years and $8.9 \%$ had $10+$ years of experience.

Overall, 1 or more parasitic organisms was detected in stool samples from 30.5\% of the workers. There was no significant seasonal variation in infection rates in different months (data not shown). Table 1 shows that there was no significant statistical difference in the rate of infection with intestinal parasites in males and females (30.6\% of males and $30.2 \%$ of females). Similarly, there was an equal distribution of parasitic infection among all ages of foodhandlers, ranging from $29.9 \%$ to $31.7 \%$.

The infection rates were also comparable for duration of work: $30.8 \%, 29.7 \%$ and $30.1 \%$ in those working for $\leq 5$ years, 6-10 years and $10+$ years respectively. As illustrated in Figure 1, the infection rate was highest among food-handlers working 


\begin{tabular}{|c|c|c|c|}
\hline Variable & No. examined & No. infected & $\%$ \\
\hline \multicolumn{4}{|l|}{ Sex } \\
\hline Male & 1394 & 426 & 30.6 \\
\hline \multirow[t]{2}{*}{ Female } & 106 & 32 & 30.2 \\
\hline & \multicolumn{3}{|c|}{$\chi^{2}=0.01, \mathrm{df}=1, P>0.05$} \\
\hline \multicolumn{4}{|c|}{ Age group (years) } \\
\hline$<21$ & 104 & 33 & 31.7 \\
\hline $21-30$ & 630 & 194 & 30.8 \\
\hline $31-40$ & 532 & 160 & 30.1 \\
\hline $41-50$ & 174 & 52 & 29.9 \\
\hline \multirow[t]{2}{*}{$\geq 51$} & 60 & 19 & 31.6 \\
\hline & \multicolumn{3}{|c|}{$\chi^{2}=2.29, \mathrm{df}=4, P>0.05$} \\
\hline \multicolumn{4}{|c|}{ Work experience (years) } \\
\hline $0-5$ & 1118 & 344 & 30.8 \\
\hline $6-10$ & 249 & 74 & 29.7 \\
\hline \multirow[t]{2}{*}{$10+$} & 133 & 40 & 30.1 \\
\hline & \multicolumn{3}{|c|}{$\chi^{2}=0.12, \mathrm{df}=2, P>0.05$} \\
\hline Total & 1500 & 458 & 30.5 \\
\hline
\end{tabular}

$d f=$ degrees of freedom.

in hotels, factories, cafeterias and restaurants and bakeries respectively, but with no significant difference. The lowest rate of infection was in butchers.

The intestinal protozoa Enta. coli was detected in $15.3 \%$ of workers, G. lamblia in 9.7\% and Enta. histolytica in $4.3 \%$. Moreover, $2.7 \%$ of food-handlers were harbouring intestinal helminths: $H$. nana $(1.6 \%)$, Sch. mansoni $(0.7 \%)$, T. saginata $(0.3 \%)$ and Str. stercoralis $(0.1 \%)$.

Direct microscopy detected intestinal protozoa in $18.6 \%$ of the food-handlers, the formol-ether technique detected them in $29.4 \%$ and the floatation technique in $12.5 \%$ of the food-handlers (Table 2). The floatation technique detected a high prevalence of $G$. lamblia in stools, followed by Enta. histolytica, but it failed to detect any cases of Enta. coli. The direct microscopy $(2.3 \%)$ and formol-ether techniques $(2.7 \%)$ were the most effective methods for detecting intestinal helminths; the floatation technique failed to detect any helminths (Table 2).

\section{Discussion}

In the present study the infectivity of intestinal helminths $(2.7 \%)$ in Sudanese food-handlers was much lower than that reported by Al Lahham et al. who found that $13.5 \%$ of non-Jordanian food-handlers working in Jordan were infected with intestinal helminths [12]. It is also much lower than that obtained by Costa-Cruz et al. in Brazil where the infection rate with intestinal helminths was $18.3 \%$ [13]. This high infectivity can be explained by the lack of annual medical examination of foodhandlers in Brazil. The helminth infection rate in the present study was higher than that reported by Tomaso et al. $(0.2 \%)$ among food-handlers in Austria [14]. The discrepancy in socioeconomic status, environmen- 


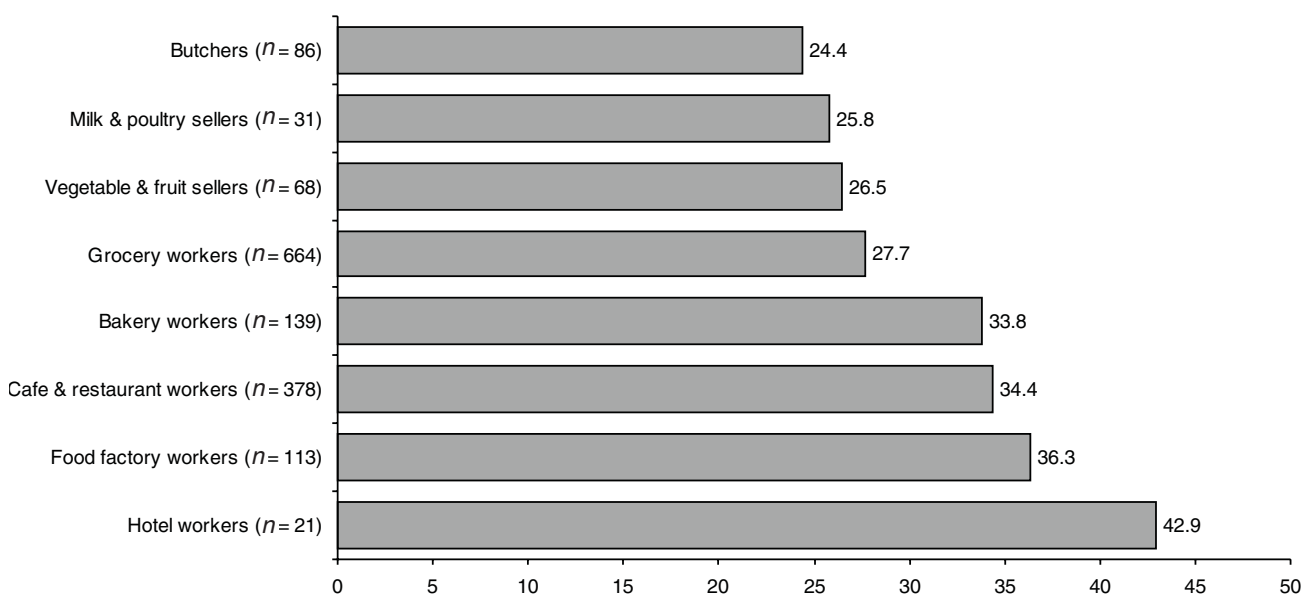

Figure 1 Frequency of intestinal parasitic infection in different occupational groups of foodhandlers ( $n=$ number examined)

tal conditions, sanitation systems, waste management and lack of personal hygiene may explain this difference.

The overall infection rate by intestinal protozoa in our study was relatively high
(29.4\%). However, it is in line with a study conducted in Jordan, where the frequency of infection by intestinal protozoa $(30.2 \%)$ was found to be higher than helminth infection $(13.5 \%)$ [12]. The similarity is likely

\begin{tabular}{|c|c|c|c|c|c|c|}
\hline \multirow[t]{2}{*}{ Intestinal parasite } & \multicolumn{2}{|c|}{ Direct microscopy } & \multicolumn{2}{|c|}{$\begin{array}{l}\text { Formol-ether } \\
\text { technique }\end{array}$} & \multicolumn{2}{|c|}{$\begin{array}{l}\text { Floatation } \\
\text { technique }\end{array}$} \\
\hline & No. & $\%$ & No. & $\%$ & No. & $\%$ \\
\hline \multicolumn{7}{|l|}{ Intestinal protozoa } \\
\hline Entamoeba coli & 137 & 9.1 & 230 & 15.3 & 0 & - \\
\hline Giardia lamblia & 112 & 7.5 & 146 & 9.7 & 124 & 8.3 \\
\hline Entamoeba histolytica & 30 & 2.0 & 65 & 4.3 & 63 & 4.2 \\
\hline Total & 279 & 18.6 & 441 & 29.4 & 187 & 12.5 \\
\hline \multicolumn{7}{|l|}{ Intestinal helminths } \\
\hline Hymenolepis nana & 20 & 1.3 & 24 & 1.6 & 0 & - \\
\hline Schistosoma mansoni & 8 & 0.5 & 11 & 0.7 & 0 & - \\
\hline Taenia saginata & 4 & 0.3 & 4 & 0.3 & 0 & - \\
\hline Strongyloides stercoralis & 2 & 0.1 & 2 & 0.1 & 0 & - \\
\hline Total & 34 & 2.3 & 41 & 2.7 & 0 & - \\
\hline
\end{tabular}


due to the similar socioeconomic status and environmental conditions. Furthermore, infection with $G$. lamblia in the present study was lower than that reported in Somalia (77\%) by Ilardia et al. in 1987 [15]. The relatively high infection rate in this area is likely due to the civil wars, which are still continuing.

No association was found between the frequency of parasite infection and age, sex, occupation, duration of work and place of work. This illustrates the equal exposure to the infection and suggests an effect of environmental conditions on infection. Undoubtedly, continuous health supervision, annual medical examination and prompt treatment of infected food-handlers minimizes the effect of duration of work on infection rates.

Although we might expect some seasonal variation in transmission of intestinal helminths, the present study failed to detect any significant variation between occurrences of the infection in different months. This differs from the studyof Nzeako in Nigeria who reported seasonality of infection with intestinal helminths [16]. Difference in climatic conditions may explain the different findings.

We conclude that the annual screening of food-handlers in Khartoum is insufficient to monitor parasitic infections and that more frequent screening, for example monthly screening, should be carried out. This could be done cheaply and effectively using direct microscopy of stool samples, which is sufficient to detect a high proportion of infestations. Further studies are recommended to evaluate the different techniques more systematically and to include pathogenic infectious organisms other than intestinal parasites.

\section{References}

1. Cheesbrough M. Medical laboratory manual for tropical countries, 2nd ed. Oxford, Butterworth, 1987.

2. Webbe G. Recent developments in cestode research. Transactions of the Royal Society of Tropical Medicine and Hygiene, 1995, 89:345-6, 353.

3. Tanowitz HB, Weiss LM, Wittner M. Tapeworms. Current infectious disease reports, 2001, 3(1):77-84.

4. Nokes C, Bundy DAP. Does helminth infection affect mental processing and education achievement? Parasitology today, 1994, 10(1):14-8.

5. Prevention and control of intestinal parasitic infections. Report of a WHO Expert Committee. Geneva, World Health Organization, 1987 (WHO Technical Report Series, No. 749).
6. Chute GG, Smith RP, Baron JA. Risk factors for endemic giardiasis. American journal of public health, 1987, 77:585-7.

7. Salih SY, Abdella RE. Symptomatic giardiasis in Sudanese adults and its treatment with tinidazole. Journal of tropical medicine and hygiene, 1977, 80(11):11-3.

8. Kasim AA, Elhelu MA. Giardiasis in Saudi Arabia. Acta tropica, 1983, 40:155-8.

9. Luaces AL, Osorio LM, Barrett AJ. A new test for infection by Entamoeba histolytica. Parasitology today, 1993, 9(2):69-71.

10. Feachem RG. Interventions for the control of diarrhoeal diseases among young children: promotion of personal and domestic hygiene. Bulletin of the World Health Organization, 1984, 62:467-76.

11. Matyás $Z$. Role of veterinarians in modern food hygiene. Bulletin of the World Health Organization, 1978, 56(5):699-711. 
12. Al-Lahham AB, Abu-Saud M, Shehabi AA. Prevalence of Salmonella, Shigella and intestinal parasites in food handlers in Irbid, Jordan. Journal of diarrhoeal diseases research, 1990, 8(4):160-2.

13. Costa-Cruz, JM, Cardoso ML, Marques DE. Intestinal parasites in school food handlers in the city of Uberlândia, Minas Gerais, Brazil. Revista do Instituto de Medicina Tropical de Sao Paulo, 1995, 37(3):191-6.

14. Tomaso H, Dierich MB, Allerberger F. Helminthic infections in the Tyrol, Austria.
Clinical microbiology and infection, 2001, 7(11):639-41.

15. Ilardia I et al. Epidemiological study of parasitic infection in Somali nomads. Transactions of the Royal Society of Tropical Medicine and Hygiene, 1987, 81(5):771-2.

16. Nzeako BC. Seasonal prevalence of protozoan parasites in Nsukka, Nigeria. Journal of communicable diseases, 1992, 24(4):224-30.

\section{Food safety and foodborne illness}

Food safety is an increasingly important public health issue. Governments all over the world are intensifying their efforts to improve food safety. These efforts are in response to an increasing number of food safety problems and rising consumer concerns.

The Work of the WHO Department of Food Safety and other WHO programmes and departments includes strengthening food safety systems, promoting good manufacturing practices and educating retailers and consumers about appropriate food handling. Education of consumers and training of food handlers in safe food handling is one of the most critical interventions in the prevention of foodborne illnesses. 